\title{
Multiparametric Correlation Between Anatomical Variants of the Paranasal Sinuses and Chronic Rhinosinusitis: Case-control Study
}

\author{
Prada William*, Medina Fernando \\ Department of Radiology and Diagnostic Images, Sabana University, Bogotá, Colombia \\ Email address: \\ Wpradamancilla@gmail.com (P. William) \\ *Corresponding author \\ To cite this article: \\ Prada William, Medina Fernando. Multiparametric Correlation Between Anatomical Variants of the Paranasal Sinuses and Chronic \\ Rhinosinusitis: Case-control Study. International Journal of Medical Imaging. Vol. 7, No. 1, 2019, pp. 18-24. \\ doi: $10.11648 /$ j.ijmi.20190701.13
}

Received: January 30, 2019; Accepted: March 7, 2019; Published: March 29, 2019

\begin{abstract}
Introduction: Chronic rhinosinusitis (RSC) is a disabling disease that can affect up to $70 \%$ of people. It is very important to know which are the anatomical variants that the patient presents for surgical planning and often for the treatment of the variants that can present as a risk factor. The evidence shows heterogeneity in the prevalence of these anatomical variants and it is not described quantitatively which are the variants that present the greatest relationship as a risk factor. Establishing the multiparametric correlation between at least one of the most frequent anatomical variants of the paranasal sinuses and the development of rhinosinusitis is the most important objective of this investigation. Materials and methods: Case-control study with multiparametric correlation analysis of the anatomical variants of paranasal sinuses as a risk factor in the development of sinusitis. Analysis with measures of central tendency, Xi2, Fisher's exact test, binary logistic regression. Results: The most frequent anatomical variant was the deviation of the nasal septum on the left side (78\%). The second most common variant found was the Agger Nasi cells (68\%), followed by the protrusion of the Vidian nerve in the sphenoid sinus (52\%). The only anatomical variant that could be determined within the regression model was the obstruction of the osteomeatal complex; which is presented as a risk factor with an OR of 16 (95\% CI: 6.9-41.3). Conclusions: Obstruction of the osteomeatal complex is a very important risk factor for the development of chronic rhinosinusitis.
\end{abstract}

Keywords: Paranasal Sinuses, Correlation, Sinusitis, Anatomical Variants

\section{Introduction}

Chronic rhinosinusitis (CRS), understood as a symptomatic inflammation of the nasal and paranasal cavities in a time greater than 12 weeks, associated with mucopurulent posterior drainage, nasal obstruction, facial pain and hyposmia; It is a disabling disease that can affect up to $70 \%$ of people in the adult population with a prevalence that increases over 60 years $[1,2]$. It is one of the reasons for more frequent outpatient consultations, presenting a higher prevalence than consultations for asthma and allergies. In Brazil it has a prevalence of $5.51 \%$, while in our country there are no population studies reported in the systematic review. Among the risk factors are cigarettes, cocaine use, asthma, allergies, immunodeficiencies, and granulomatous diseases, among others. The anatomical variants as a risk factor have not been clearly established due to diverse results in the majority of published studies $(3,4)$.

Azila et al, in 2011 showed that the anatomic variants most commonly associated with the development of CRS was the presence of a paradoxical middle turbinate and the infraorbital ethmoidal cells (3). In 2012 Fadda et al, found that several of the variants are associated with the development of CSR, within which are the deviation of the nasal septum, the presence of concha bullosa and deviation from the uncinate process [5, 6]. In 2016 Raluca et al, found that the associated statistically significant anatomical variants were concha bullosa alterations, deviation from the uncinate process and an asymmetric ethmoidal roof [7[. On the other hand, Ahmet et al, in 2014 reported a retrospective study of 
100 patients that there is no relationship between the anatomical variants and the development of CSR [8]. At present, it is not clear what is the true relationship as a risk factor for anatomical variants in the development of CSR. Despite the above, the literature reports that it is important to know and include in the radiological report the main anatomical variants that may be related to the development of this disease and guide the treating physician for its diagnostic and therapeutic approach $[9,10,11]$.

Likewise, when the surgical treatment of this pathology is decided according to its severity, it is very important for the otolaryngologist (OTL) to know the most frequent anatomical variants, since an injury of these can lead to complications of the central nervous system, injury of the Related optical nerves, and alterations of the optic canal. Knowing the anatomical variants can guide the surgeon to correct defects that may be associated with the development of chronic rhinosinusitis in patients and achieve adequate paranasal drainage to reduce recurrence $[12,13,14]$. That is why, the present investigation evaluates the relationship of the anatomical variants with the development of rhinosinusitis and determines which is the most strongly associated variant.

\section{Methods}

This is a case-control study with multiparametric correlation analysis for the construction of the prediction model of the anatomical variants of the paranasal sinuses as risk factors in the development of sinusitis. It was an analytical study with simple random probabilistic sampling. This research was conducted in the clinic of the University of the Sabana in Bogota, Colombia, during the years 20152017. The study was approved by the clinical technical committee of the clinic.

\subsection{Selection Criteria}

Paranasal sinus scans of patients over 18 years of age with diagnostic impression of chronic rhinosinusitis were included and sent to the clinic for the paranasal sinus tomography. Patients with incomplete reconstructions were excluded for the evaluation of the anatomical variants in an adequate manner in the tomographic studies, patients with surgical procedures on the face and base of the skull related to the paranasal sinuses before the tomography, and patients with associated pathologies, such as cystic fibrosis, polyposis, mycetoma, and odontogenic sinusitis. The case was defined as the paranasal sinus scans which had the diagnosis of remission by the treating physician of chronic rhinosinusitis.

\subsection{Study Size}

A probabilistic sample calculation was performed for cases and controls. Regarding the systematic search, a value of 142 patients was established, with a number of controls per case of one (71 cases and 71 controls). This sample size was determined with a proportion of exposed cases of $53 \%$ and exposed controls of $30 \%$, with an Odds ratio to be detected of 2,6 and a confidence level of $95 \%$. Finally, a power of $80 \%$ was established for the control of the universally accepted beta type error.

\subsection{Statistical Methods}

The dependent variable defined in this research by the researchers was the diagnostic impression of remission of chronic sinusitis by the attending physician, while the independent variables were the different anatomical variants related to the paranasal sinuses. For the analysis plan of the study, an univariate analysis was established, which was established by frequency and percentage tables. On the other hand, for the quantitative variables such as age, measures of central tendency were established. The quantitative variables were subjected to normality tests using the shapiro wilk and kolmogorov smirnov test; which gave a non normal distribution for the age and the severity variable of the disease. Due to the above, the median and interquartile (IQ) values were presented. For the secondary analysis, the xi2 test or Fisher's exact test was performed according to the expected values; These tests were carried out to establish if there was a relationship between the qualitative variables and the dependent variable. For the quantitative variables, the Mann withney test was performed, a non-parametric test for ordinal variables. pearson correlation analysis was performed for the evaluation of the clinical indication versus tomographic findings.

\subsection{Data Measurement}

Data collection was done from the primary source through the principal investigators. Likewise, the investigators made the additional measures if they were not found in the report. After the analysis and interpretation, they were entered into an on-line Google-format type database, which was exported to the IBM-SPSS V23.0 program and Stata 13 for statistical analysis.

A pilot study was carried out with a sample size calculated by the Viecthbauer method of the total sample (15 patients), evaluating the main anatomical variants of the tomography images of the patients until finding a level of agreement with the Kappa statistic greater than $75 \%$ between the two evaluators of the images. Likewise, the pilot study allowed to establish the amendments of the protocol, including the exclusion of measurement variables, method of patient selection in primary data source and exclusion criteria of patients with poor technique in obtaining tomographic images.

\section{Results}

An initial analysis of 222 sinus tomography was performed, where 80 were excluded by selection criteria, leaving 142 tomographies for the analysis (Figure 1). 


\section{2 sinus tomography}

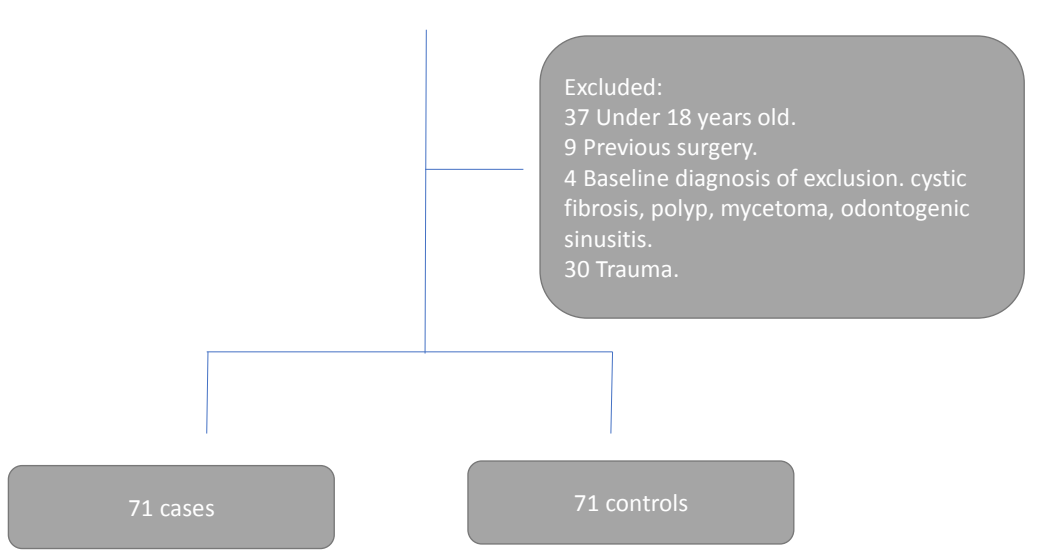

Figure 1. Flowchart of selection criteria.

\subsection{Social and Demographic Variables}

It was found that $57 \%$ of the population was women, while the median age was 49 years with a range between 18 and 84 years (Table 1).

Table 1. More frequent anatomical variants.

\begin{tabular}{|c|c|c|c|}
\hline Variable & Classification & $\mathbf{N}$ & Marginal percentage \\
\hline \multirow[t]{2}{*}{ Tomographic sinusitis } & No & 98 & $69,00 \%$ \\
\hline & Yes & 44 & $31,00 \%$ \\
\hline \multirow[t]{4}{*}{ Location of Tomographic sinusitis } & Without sinusitis CT & 99 & $69,70 \%$ \\
\hline & Left & 8 & $5,60 \%$ \\
\hline & Right & 9 & $6,30 \%$ \\
\hline & Bilateral & 26 & $18,30 \%$ \\
\hline \multirow[t]{5}{*}{ Affected paranasal sinuses } & Without sinusitis CT & 98 & $69,00 \%$ \\
\hline & Right Maxillary & 5 & $3,50 \%$ \\
\hline & Left Maxillary & 3 & $2,10 \%$ \\
\hline & Ethmoidal anterior right & 1 & $0,70 \%$ \\
\hline & Sphenoidal & 1 & $0,70 \%$ \\
\hline \multirow[t]{2}{*}{ Deviation of the nasal septum } & No & 34 & $23,90 \%$ \\
\hline & Yes & 108 & $76,10 \%$ \\
\hline \multirow[t]{4}{*}{ Lateralización del Septum desviado } & Without obstruction & 34 & $23,90 \%$ \\
\hline & Right & 39 & $27,50 \%$ \\
\hline & Left & 47 & $33,10 \%$ \\
\hline & Sinuous & 22 & $15,50 \%$ \\
\hline \multirow[t]{2}{*}{ Agger Nasi's cells } & No & 45 & $31,70 \%$ \\
\hline & Yes & 97 & $68,30 \%$ \\
\hline \multirow[t]{3}{*}{ Lateralization cells of agger nasi } & No presence of Agger Nasi cells & 59 & $41,50 \%$ \\
\hline & Right & 2 & $1,40 \%$ \\
\hline & Bilateral & 81 & $57,00 \%$ \\
\hline \multirow[t]{2}{*}{ Protrusion of the vidian nerve in the sphenoidal sinus } & No & 75 & $52,80 \%$ \\
\hline & Yes & 67 & $47,20 \%$ \\
\hline \multirow[t]{2}{*}{ Concha bullosa } & No & 89 & $62,70 \%$ \\
\hline & Yes & 53 & $37,30 \%$ \\
\hline \multirow[t]{2}{*}{ Intersinuous frontal septal cells } & No & 90 & $63,40 \%$ \\
\hline & Yes & 52 & $36,60 \%$ \\
\hline \multirow[t]{2}{*}{ Nasal spur } & No & 93 & $65,50 \%$ \\
\hline & Yes & 49 & $34,50 \%$ \\
\hline \multirow[t]{3}{*}{ Lateralization of the nasal spur } & Without spur & 95 & $66,90 \%$ \\
\hline & Right & 16 & $11,30 \%$ \\
\hline & Left & 31 & $21,80 \%$ \\
\hline
\end{tabular}




\begin{tabular}{|c|c|c|c|}
\hline Variable & Classification & $\mathbf{N}$ & Marginal percentage \\
\hline \multirow[t]{2}{*}{ Supra-orbital ethmoid cells } & No & 99 & $69,70 \%$ \\
\hline & Yes & 43 & $30,30 \%$ \\
\hline \multirow{2}{*}{ Obstruction of the osteomeatal complex } & No & 101 & $71,10 \%$ \\
\hline & Yes & 41 & $28,90 \%$ \\
\hline \multirow[t]{4}{*}{ Location of the obstructed complex } & Without obstruction & 100 & $70,40 \%$ \\
\hline & Right & 13 & $9,20 \%$ \\
\hline & Left & 11 & $7,70 \%$ \\
\hline & Bilateral & 18 & $12,70 \%$ \\
\hline \multirow[t]{2}{*}{ Onodi Cells } & No & 103 & $72,50 \%$ \\
\hline & Yes & 39 & $27,50 \%$ \\
\hline \multirow[t]{2}{*}{ Hypoplasia of the frontal sinus } & No & 103 & $72,50 \%$ \\
\hline & Yes & 39 & $27,50 \%$ \\
\hline \multirow[t]{2}{*}{ Hypoplasia of the maxillary sinus } & No & 113 & $79,60 \%$ \\
\hline & Yes & 29 & $20,40 \%$ \\
\hline \multirow[t]{2}{*}{ Ostium accessory } & No & 121 & $85,20 \%$ \\
\hline & Yes & 21 & $14,80 \%$ \\
\hline \multirow[t]{2}{*}{ Paradoxical incurvation of the middle turbinates } & No & 126 & $88,70 \%$ \\
\hline & Yes & 16 & $11,30 \%$ \\
\hline \multirow[t]{2}{*}{ Kuhn's Cells } & No & 119 & $83,80 \%$ \\
\hline & Yes & 23 & $16,20 \%$ \\
\hline \multirow[t]{4}{*}{ Kuhn cell type } & sin celdillas de Kuhn & 119 & $83,80 \%$ \\
\hline & Type 1 & 14 & $9,90 \%$ \\
\hline & Type 2 & 8 & $5,60 \%$ \\
\hline & Type 3 & 1 & $0,70 \%$ \\
\hline \multirow[t]{2}{*}{ Protrusion of the maxillary nerve V2 in the sphenoid sinus } & No & 118 & $83,10 \%$ \\
\hline & Yes & 24 & $16,90 \%$ \\
\hline \multirow[t]{2}{*}{ Ethmoidal roof height } & 3-7 mm & 43 & $30,30 \%$ \\
\hline & $>7 \mathrm{~mm}$ & 99 & $69,70 \%$ \\
\hline
\end{tabular}

\subsection{Anatomical Variants of the Paranasal Sinuses}

Of the 142 studies analyzed, it was established that $31 \%$ had tomographic findings of sinusitis; which, were interpreted by the radiologist. Of these, $18 \%$ had bilateral commitment, $6 \%$ right commitment and 5\% left commitment. The most affected paranasal sinus was the right maxilla. Nevertheless; in $24 \%$ of the cases the commitment was in more than one paranasal sinus. The most frequent anatomical variant was the deviation of the nasal septum, being more frequent on the left side. The second most common variant found was the Agger Nasi cells, followed by the protrusion of the Vidian nerve in the sphenoid sinus. The presence of concha bullosa and nasal spur were also frequent within the anatomical variants found. The obstruction of the osteomeatal complex was present in $29 \%$ of the patients, being more frequent to bilateral obstruction. The paradoxical incurvation of the middle turbinates was present in $11 \%$ of the studies analyzed. The Kuhn cells were presented in $16 \%$, with type 1 being more frequent (table 1). The rest of anatomical variants were presented with a percentage lower than $10 \%$.

\subsection{Concordance Between Clinical Diagnostic Impression and Tomographic Findings}

It was found that 29 scans of the 71 that were included by medical diagnostic printing had tomographic findings of sinusitis, while 15 tomographies of those that were included for another clinical suspicion presented tomographic findings of sinusitis (Table 2). A Pearson correlation analysis was performed, finding only a correlation percentage of $11 \%$.

Table 2. Table $2 \times 2$ of correlation between clinical and images by tomography for the diagnosis of sinusitis.

\begin{tabular}{|c|c|c|c|c|}
\hline \multirow{2}{*}{ Tomographic sinusitis * Indication of cross tabulated tomography } & & \multicolumn{2}{|c|}{ Tomography indication } & \multirow{2}{*}{ Total } \\
\hline & & Sinusitis & Other & \\
\hline \multirow{2}{*}{ Tomographic sinusitis } & No & 42 & 56 & 98 \\
\hline & Yes & 29 & 15 & 44 \\
\hline Total & & 71 & 71 & 142 \\
\hline
\end{tabular}

\subsection{Multiparametric Correlation Between Anatomical Variants and Presence of Sinusitis in Tomography}

Of all the anatomical variants included in the forward regression model for the correlation as a risk factor in the development of sinusitis, the only anatomic variant that could be determined within the regression model was obstruction of the osteomeatal complex; which is presented as a risk factor with an OR of 16 (95\% CI: 6.9-41.3). Likewise, it has a statistically significant direct relationship with the severity of 
the disease $(\mathrm{p}<0.001)$.

\section{Discussion}

In our investigation, a rigorous analysis was made of the most frequent anatomical variants found in a probabilistic sample with simple random assignment in a health institution in Bogotá, Colombia. A collection of tomography images with a special protocol for paranasal sinuses was carried out for two and a half years. We excluded approximately 80 studies that did not meet all of the selection criteria, and 142 CT scans were included in an ideal ratio of one case for each control.

Our study showed that the most common variant is the deviation of the nasal septum, being more frequent on the left side as reported by other authors [5, 15]. The literature reports that, apart from septal deviation, concha bullosa and nasal spurs are the most frequent variants. Nevertheless; it is striking that in our study the second most frequent variant was the presence of Agger Nasi cells in $68 \%$, being $57 \%$ of the time of bilateral appearance (figure 2). Most studies do not report this variant with such a high frequency. Despite this, studies with prevalence up to $97 \%$ are found, where it is argued that the lack of probabilistic sampling and the ratio of cases vs controls generally greater than 1: 1 in this type of studies exclude that it is found so frequently this anatomical variant $[16,17]$. It is very important to know that this anatomical variant has a high prevalence in our population, since including in the tomographic report this variant allows the Otorhinolaryngologist to propose a better therapeutic approach in this disease (12). Likewise, although this variant has no association with the development of the disease in our study, it can generate a point of approach for the surgeon in patients who develop chronic frontal sinusitis.

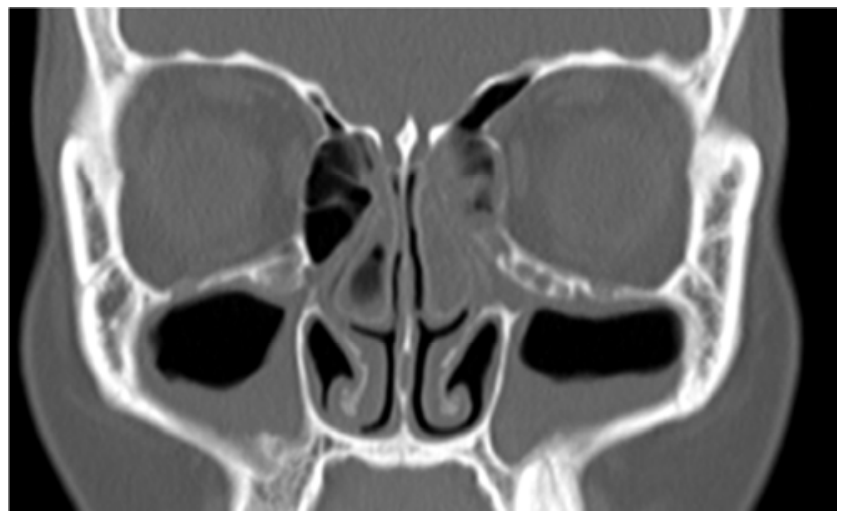

Figure 2. Agger Nasi cells with bilateral maxillary sinusitis.

Among the other more frequent variants found in our study, there is also the presence of concha bullosa, supraorbital cells and Kuhn cells, which are not so frequently reported in tomography reports. Likewise, attention is drawn to the high frequency of the protrusion of the vidian nerve and the maxillary nerve (V2), which can become important when the sphenoid sinus is affected. Knowing and reporting these anatomical variants in tomographic studies generates a greater understanding of the symptomatology of these patients and often the relationship they may present with neurological symptoms $[18,19]$.

Although there are some studies that report that anatomical variants do not influence the surgical approach of patients with paranasal pathology, we believe that taking into account anatomical variants other than those already described may be related to the development of paranasal disease and they are important for the surgeon; as is the case of the height of the ethmoidal roof, since in the studied population it was found that $70 \%$ of the time it presents with depression greater than $7 \mathrm{~mm}$, allowing an ethmoidal infection to rise more easily and develop infectious diseases of the central nervous system (figure 3,4 ).

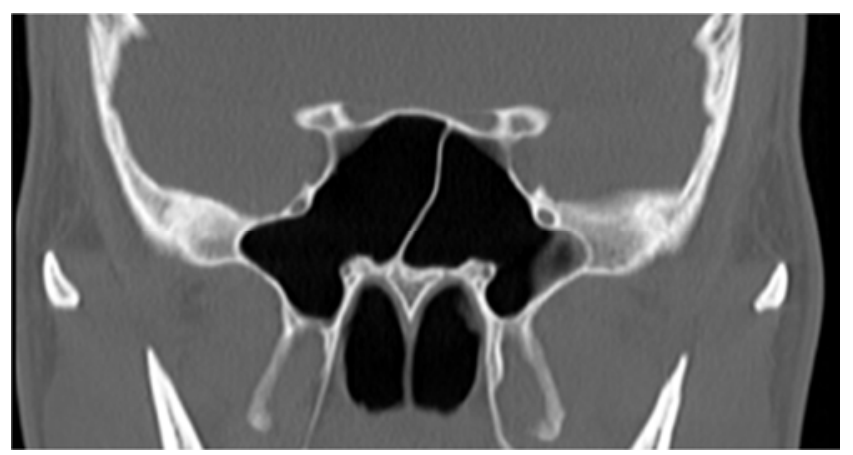

Figure 3. Protrusion of the Vidian nerve in the sphenoid sinus.

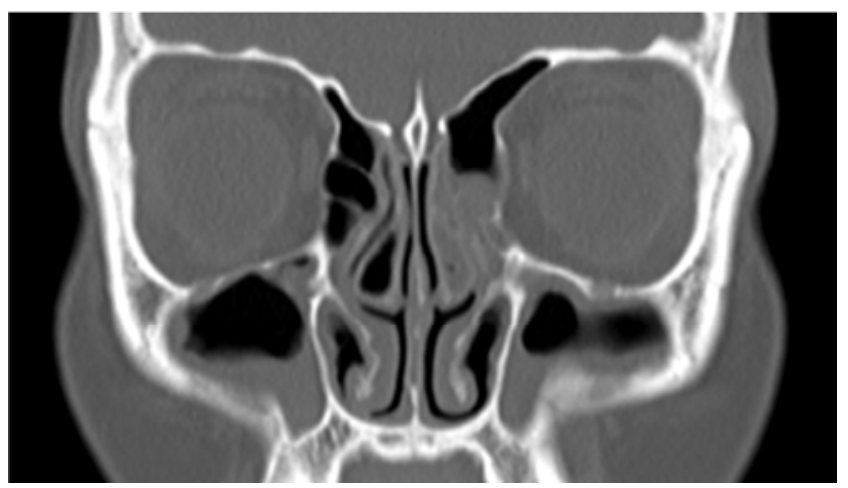

Figura 4. Depth of the ethmoidal roof greater than $7 \mathrm{~mm}$.

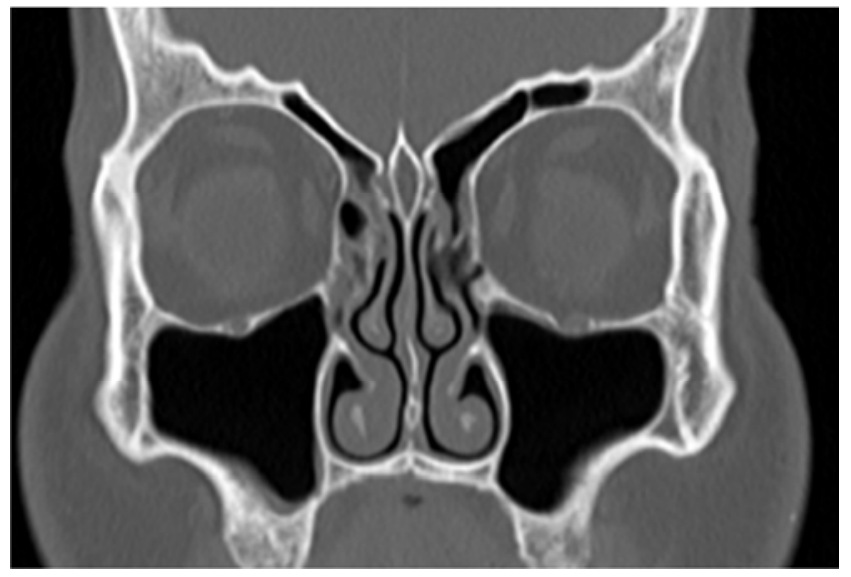

Figura 5. Obstruction of the bilateral ostiomeatal complex.

The relationship between anatomical variants as a risk 
factor for development is very inconsistent in the literature, being for some authors the deviation of the septum a risk factor for sinusitis, while for others they do not have statistical significance. In our study, the only variant that presented as a risk factor was obstruction of the osteomeatal complex, with an OR of 16 (CI: 6.9-41). This allows to clarify that, in our study population, despite the high frequency of many anatomical variants, the most important factor as a risk factor is the obstructed osteomeatal complex (figure 5). Likewise, it was found that it has a statistically significant direct relationship with the severity of the disease $(\mathrm{p}<0.001)$ as established in the Lun Mackay classification $[20,21,22]$.

On the other hand, it is striking that the correlation between the clinical diagnostic impression and the tomographic findings found was very low, only $11 \%$. This means that many times the patient may present masked symptoms in relation to some of the anatomical variants described and the presence of sinus pathology, being for the physician the primary radiologist to always report the most frequent variants and even more the variants that are more related to the development of this disease [23, 24].

This study presents as limitations, not having been carried out prospectively since more memory biases had been controlled; However, the necessary data were found in all the diagnostic images analyzed. Despite this, due to this limitation, many more tomographic studies had to be excluded. Another limitation, which was obtained, was that no confirmation was made of the mid-endoscopic tomographic diagnoses.

\section{Conclusions}

Obstruction of the osteomeatal complex is a very important risk factor for the development of chronic rhinosinusitis (OR: 16, CI: 6.9-41). Associated with this anatomical variant, the most frequent in the studied population are the deviation of the nasal septum, the presence of Agger Nasi cells, the protrusion of the Vidian nerve in the sphenoid sinus and the presence of Concha Bullosa. It is important for the radiologist to report these types of variants whenever he / she is faced with a sinus tomography, as they can be very useful for the surgeon and does not always correlate with the clinical indications of inflammatory sinus disease.

\section{Acknowledgements}

We are grateful for the support of the Clinic of the University of La Sabana for allowing the development of this research project, to the teachers and associate partners that allowed a better development of the project and the administrative staff of the radiology unit and diagnostic images. Finally, to the patients who participated in the study for allowing a better development of our specialty in the country.

\section{References}

[1] Hamilos DL. Chronic rhinosinusitis: epidemiology and medical management. J Allergy Clin Immunol. 2011; 128(4):693-707; quiz 8-9.

[2] Herzallah IR, Hamed MA, Salem SM, Suurna MV. Mucosal contact points and paranasal sinus pneumatization: Does radiology predict headache causality? Laryngoscope. 2015; 125(9):2021-6.

[3] Tramontini, C MA, Mora J, Ordoñez L. Variantes anatómicas de los senos paranasales: hallazgos por imagen y relevancia quirúrgica. Rev. Medica. Sanitas 2015. p. 39-43.

[4] Jain R, Stow N, Douglas R. Comparison of anatomical abnormalities in patients with limited and diffuse chronic rhinosinusitis. Int Forum Allergy Rhinol. 2013; 3(6):493-6.

[5] Fadda GL, Rosso S, Aversa S, Petrelli A, Ondolo C, Succo G. Multiparametric statistical correlations between paranasal sinus anatomic variations and chronic rhinosinusitis. Acta Otorhinolaryngol Ital. 2012; 32(4):244-51.

[6] Sadr SM, Ahmadinejad M, Saedi B, Razaghian F, Rafiee M. Anatomical variations in sinus imaging in sinusitis: a case control study. B-ent. 2012; 8(3):185-9.

[7] Roman RA, Hedesiu M, Gersak M, Fidan F, Baciut G, Baciut M. Assessing the prevalence of paranasal sinuses anatomical variants in patients with sinusitis using Cone Beam Computer Tomography. Clujul Med. 2016; 89(3):419-21.

[8] Kaygusuz A, Haksever M, Akduman D, Aslan S, Sayar Z. Sinonasal anatomical variations: their relationship with chronic rhinosinusitis and effect on the severity of disease-a computerized tomography assisted anatomical and clinical study. Indian J Otolaryngol Head Neck Surg. 2014; 66(3):2606.

[9] Jorissen M, Hermans R, Bertrand B, Eloy P. Anatomical variations and sinusitis. Acta Otorhinolaryngol Belg. 1997; 51(4):219-26.

[10] Rosenfeld RM, Piccirillo JF, Chandrasekhar SS, Brook I, Ashok Kumar K, Kramper M, et al. Clinical practice guideline (update): adult sinusitis. Otolaryngol Head Neck Surg. 2015; 152(2 Suppl): S1-S39.

[11] Scribano E, Ascenti G, Cascio F, Racchiusa S, Salamone I. [Computerized tomography in the evaluation of anatomic variations of the ostiomeatal complex]. Radiol Med. 1993; 86(3):195-9.

[12] Jones NS. CT of the paranasal sinuses: a review of the correlation with clinical, surgical and histopathological findings. Clin Otolaryngol Allied Sci. 2002; 27(1):11-7.

[13] Adeel M, Rajput MS, Akhter S, Ikram M, Arain A, Khattak YJ. Anatomical variations of nose and para-nasal sinuses; CT scan review. J Pak Med Assoc. 2013; 63(3):317-9.

[14] Tiwari R, Goyal R. Study of Anatomical Variations on CT in Chronic Sinusitis. Indian J Otolaryngol Head Neck Surg. 2015; 67(1):18-20.

[15] Dasar U, Gokce E. Evaluation of variations in sinonasal region with computed tomography. World J Radiol. 2016; 8(1):98-108. 
[16] Shin JM, Baek BJ, Byun JY, Jun YJ, Lee JY. Analysis of sinonasal anatomical variations associated with maxillary sinus fungal balls. Auris Nasus Larynx. 2016; 43(5):524-8.

[17] Rosenfeld RM, Piccirillo JF, Chandrasekhar SS, Brook I, Kumar KA, Kramper M, et al. Clinical practice guideline (update): Adult Sinusitis Executive Summary. Otolaryngol Head Neck Surg. 2015; 152(4):598-609.

[18] Lee JH, Kim HJ, Hong YH, Kim KS. Underestimation of Rhinogenic Causes in Patients Presenting to the Emergency Department with Acute Headache. Acta Neurol Taiwan. 2015; 24(2):37-42.

[19] van Lindert EJ, Ingels K, Mylanus E, Grotenhuis JA. Variations of endonasal anatomy: relevance for the endoscopic endonasal transsphenoidal approach. Acta Neurochir (Wien). 2010; 152(6):1015-20.

[20] Lund VJ, Kennedy DW. Staging for rhinosinusitis. Otolaryngol Head Neck Surg. 1997; 117(3 Pt 2): S35-40.
[21] Angélico Jr FV, Rapoport PB. Analysis of the Agger nasi cell and frontal sinus ostium sizes using computed tomography of the paranasal sinuses. Braz J Otorhinolaryngol. 2013; 79(3):285-92.

[22] Landsberg R, Friedman M. A computer-assisted anatomical study of the nasofrontal region. Laryngoscope. 2001; 111(12):2125-30.

[23] Yenigun A, Fazliogullari Z, Gun C, Uysal, II, Nayman A, Karabulut AK. The effect of the presence of the accessory maxillary ostium on the maxillary sinus. Eur Arch Otorhinolaryngol. 2016; 273(12):4315-9.

[24] Vogiatzi T, Kloukos D, Scarfe WC, Bornstein MM. Incidence of anatomical variations and disease of the maxillary sinuses as identified by cone beam computed tomography: a systematic review. Int J Oral Maxillofac Implants. 2014; 29(6):1301-14. 